\title{
Empirical Study of Theory of Reason Action (TRA) \\ Model for ICT Adoption among the Malay Based SMEs in Malaysia
}

\author{
Syed Shah Alam (Corresponding author) \\ School of Management, Faculty of Economics and Management, Universiti Kebangsaan \\ Malaysia (UKM), 43600 UKM Bangi, Selangor, Malaysia
}

Tel: 603-8921-3724 E-mail: shahalam@ukm.my

Mohd Fauzi Mohd Jani

Center for Entrepreneurship and SMEs Development (CESMED), Universiti Kebangsaan Malaysia (UKM), 43600 UKM Bangi, Selangor, Malaysia

Nor Asiah Omar

School of Management, Faculty of Economics and Management, Universiti Kebangsaan Malaysia (UKM), 43600 UKM Bangi, Selangor, Malaysia

Tel: 603-8921-3737 E-mail: norasiah@ukm.my

Tareq Hossain

Pusat Pengajian Inovasi Perniagaan dan Teknousahawan (PPIPT)

Universiti Malaysia Perlis, Malaysia 
Mst. Nilufar Ahsan

Faculty of Management, Multimedia University, Malaysia (MMU), 63100 Cyberjaya, Selangor, Malaysia

The research is financed by: Universiti Kebangsaan Malaysia (UKM) internal grant 2011-2012

Received: November 7, 2012 Accepted: December 2, 2012 Published: December 31, 2012

doi:10.5296/bms.v3i2.2911 URL: http://dx.doi.org/10.5296/bms.v3i2.2911

\begin{abstract}
Information and communication technology (ICT) plays very crucial role to enhance sales, expand business, reduce operating cost, reduce operating procedure, improve product or company image and easy access for product information in today's competitive world. Although, the intention to use ICT is significantly depends on the attitude and social norms of executives towards ICT, especially in SME level. The main objective of the present article is to examine the determinants of ICT adoption among Malay based SMEs in Malaysia. Theory of Reasoned Action (TRA) has been employed to measure main factors that have effect on ICT adoption. The paper is based on review of literature and primary data. Data were gathered through questionnaire survey of 199 SMES in Malaysia. Hypothetical relationships were identified using multiple regression analysis in this research. The findings of this study are discussed and conclusion and policy implication are also addressed here.
\end{abstract}

Keywords: ICT adoption, Malaysia, SMEs, Percept usefulness theory 
SMEs are playing important role in every economy. Start from bigger economy like, US or China to any small economy everywhere SMEs have been playing an important role in economic reform and development and, to some extent, have become a growth engine in the economy (Wang, 2009). Alike other country, SMEs are playing very pivotal role for the economic development in East Asia, like Malaysia, Singapore etc (Harvie, 2004). Considering the importance, this research intended to examine the determinants of ICT adoption among the Malay based SMEs in Malaysia.

Malaysia is one of the multiracial country in the world, citizen like Malay, Chinese and Indians are three major races lives peacefully (Goh and Parasakthi, 2001). Malaysian progress is one of milestone in the world due to the unique relationships with all three races. Chinese are more aggressive in business, where as Malay entrepreneurs are not that level and inexperienced, less involvement in business, late participation in business, are not creative and innovative in nature. Malaysian business as well as SMEs sectors is dominating by Chinese ethnic group which is well researched (Jesudason, 1997, Nagata, 1974). Actually, in Southeast Asia the Chinese ethnic has strong network, which allows Malaysian Chinese ethnic group to added leverage in the business arena (Harianto, 1999). Unfortunately, it leads to unsustainable economic development among the different ethnic groups in Malaysia. Hence, this study focus on ICT adoption within Malay based SMEs.

The objective of this research is to review very recent research in this area and to examine the determinants that affect ICT adoption among Malay based SMEs using primary data. The author considered ICT as an important instrument to achieve competitive advantages. There are number of research shown empirical evidence that ICT brought numerous benefits for a business corporation. The current study will show how these benefits works as subjective norms and directly influence on executives intention to adopt ICT. The paper will also urge that the attitude of executives and subjective norms jointly influence on ICT adoption within Malaysian SMEs.

In this paper we used theory of reasoned action to measure the determinants of ICT adoption. According to the theory, the intention of executives significantly depends on the subject norms and attitude of executives. Current research strongly urges that the prospect of ICT deeply the depends on the executives intention in the SMEs in Malaysia. The researchers collected data from 199 responds (executives of SMEs) and used regression analysis to explain the relation. 


\section{MInstitute Mach $^{\text {Mng }}$}

\section{Evidence from Early Research}

Small and medium sized enterprises known as the SMEs refers business entity whose employee numbers or annual sales turn-over falls under certain limitation. There is no unique definition or not possible to have a single definition of the term SME, since the term has been defined by the Government of each county based on their need. In Malaysia, SMEs play a vital role towards economic development (Saleh and Ndubisi, 2006). There are number of research address on the contribution of SMEs in Malaysian economic development (Chong et al., 2009, Aris, 2007, Abdullah, 2002). SMEs are an important element in all economy because the SMEs are providing a substantial employment opportunities (Perrini et al., 2007). Other research finding shows SMEs contribute approximately 70 per cent to the UK gross domestic product and nearly 90 per cent to employment (Quayle, 2003). In Malaysia, 89.3 percent business companies are SMEs (Saleh and Ndubisi, 2006). Knowing the importance of SMEs and their contribution in economic development, this study chooses SMEs.

In this global village, the competition has been increase tremendously, which puts SMEs under considerable pressure. Through the rapid spread of information and communication technologies (ICT) and low cost than ever before, markets in different parts of the world become more integrated. Therefore, it is very important for SMEs to adopt ICT to cope with these new challenges. A survey on Italian SMEs shows that the use of ICT is increasing and the higher educated employees influence SMEs to adopt ICT (Lucchetti and Sterlacchini, 2004). Not only in Italy, but also in other country like United Kingdom the use of ICT become popular. A study on England based 378 SMEs investigate types of ICT use in UK region, prevents and facilitates the adoption and use of ICT amongst these firms, and SMEs information on ICT acquiring system. The survey suggests that most SMEs are in positively inclined towards adoption and use of ICT in UK. However, this adoption and use of ICT is mainly focused on operational matters (like online sales, customer care and so on). The research on ICT adaptation also increase various couriers like, China (Song et al., 2009), Sri-Lanka (Punchihewa and Wimalaratne, 2009), New Zealand (Locke, 2004), Malaysia (Alam and Ahsan, 2007).

The reason behind this overwhelm interest on ICT is the numbers of benefits behind the adoption of ICT. Several studies finding shows that use of ICT increase sales (Ashrafi and Murtaza, 2008, Davidavičiene, 2008). Study found that ICT can reduce business costs (Christiaanse and Kumar, 2000) and improve productivity (Oulton, 2002, Gelauff et al., 2004). Adaptation of ICT is not only strengthen growth possibilities but also creating network with all other business in the world, can have cooperation, and can improve quality and knowledge (Barba-Sanchez et al., 2007). 


\section{MInstitute Macrothink $_{\text {Intion }}$}

3. Theoretical Framework

As mentioned earlier, this study used theory of reasoned action (TRA) as theoretical basis to measure the factors that influence ICT adoption among the SMEs in Malaysia. Behavioral intention predicts by the Theory of Reasoned Action (TRA), which influences the decision or prospect of any action. The theory also used to spanning the predictions of attitude and behavior. According to (Fishbein and Ajzen (1975) this theory was developed by Martin Fixhbein and Icek Ajzen. The theory was "born largely out of frustration with traditional attitude-behavior research"(Hale et al., 2002). Theory of Reasoned Action (TRA was derived from previous research focus mainly on attitude, ultimately discussed on attitude and behavior. Theory of Reasoned Action constructs with three components i.e. behavioral intention (BI), attitude (A) and subjective norm (SN). According to TRA person's behavioral intention depends on the attitudinal behavior of the person and subjective norms $(\mathrm{BI}=\mathrm{A}+\mathrm{SN})$. If any person intends to do a behavior that person will does it.

Miller (2005) defines each of the three components of the theory as follows; "Attitudes is the sum of beliefs about a particular behavior weighted by evaluations of these beliefs". Miller (2005) defined "ssubjective norms is looks at the influence of people in one's social environment on his/her behavioral intentions; the beliefs of people". For example; some of your friends always encourage you join them who are avid exercisers. However, your spouse might prefer a more sedentary lifestyle and scoff at those who work out. The beliefs of these people, weighted by the importance you attribute to each of their opinions, will influence your behavioral intention to exercise, which will lead to your behavior to exercise or not exercise. Miller (2002) argued that "behavioral intention is a function of both attitudes toward a behavior and subjective norms toward that behavior, which has been found to predict actual behavior". The researcher also argued that "person's attitudes about exercise combined with the subjective norms about exercise, each with their own weight, will lead you to your intention to exercise (or not), which will then lead to your actual behavior (Miller, 2002)".

Based on the theory, this study assumes few factors as subjective norms, which are beliefs of people or the early research findings. These are; ICT increase sale (Ashrafi and Murtaza, 2008), expand company size (Davidavičiene, 2008), and reducing operational procedures including communicational time with global partners and access time collect resources information, reduce the time to access resources information), competitive advantages and provide easy access for product information (Barba-Sánchez et al., 2007). Hence the research framework is as following; 


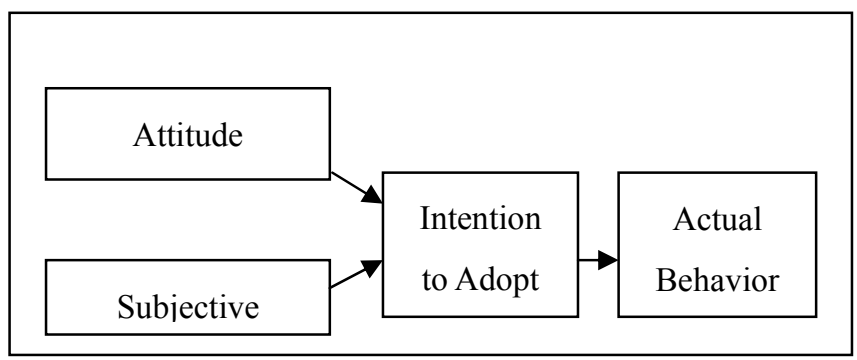

Figure 1.1. Theoretical Framework of ICT adoption

This study also considers few asking from the respondents as attitude and intention of respondents towards ICT adoption. The above Figure 1 shows that theoretical framework of this study. Based on TRA, the aim of the current study is to examine the determinants that affect ICT adoption within the Malay based SMEs. The figure shows that ICT adoption is depend on subjective norms (beliefs or the finding of ICT early research), attitude of executives.

\section{Hypothesis Development}

There are number of research provide evidence that attitude has significant influence on intention (Bentler and Speckart, 1979), which is the basis of theory of reasoned action (TRA). TRA has been employed by number of researchers, they found attitude of respondents influencing intention. A group of researcher investigate, what motivate teachers to use ICT (Cox et al., 2000), using the TRA theory author concluded that the attitude of executives to get easy access of technology influence intention of teacher. Hence, hypothesis of this study is as following;

\section{H1: Attitude of executives has no influence on intention to adopt ICT}

A number study found several benefits to adopt ICT, including; ICT increase sale (Ashrafi and Murtaza, 2008), expand company size (Davidavičiene, 2008), and so on. The finding of the early research has been considered as belief of researcher. This study considered sum of all the benefits as subjective norms. Thus, the second hypothesis is as following;

H2: Subjective norm has no influence on ICT adoption. 


\section{MInstitute Macrothink $_{\text {Intion }}$}

5. Methodology

\subsection{Data Collection}

A cross-sectional research design was used to examine the determinants that affect ICT adoption among Malay based SMEs in Malaysia. To find out the lists of SMEs in this research we sought it from the Majlis Amanah Rakyat (MARA). Malay was chosen for this study because Malaysia has a majority of Malay population as compared to other races. Personal administered questionnaire were used to collect data from the respondents. Total 500 survey questionnaire were sent to randomly selected SMEs from the lists enclosing with return envelops

We included a cover letter, a questionnaire and also envelope stamped properly. In this research questionnaires were mailed through traditional mail to the respondents. The targeted respondents were the SMEs owner, because in the owner of the SMEs made every decision related to business, thus projecting the research more clearly. Twenty-seven envelopes were returned either due to an incorrect mailing address or because the organizations were no longer existed.

However, total of 212 questionnaires were returned to the researchers (response rate was 42.4\%). Moreover, 13 questionnaires were discarded due to incomplete responses and finally 199 completed questionnaires were used for analysis. According to Macpherson and Wilson (2003) reported that it is not easy to the researchers to engage owners/manager of SMEs in research and finally low response rate is occur for all research in SMEs areas. It is a common problems facing by the other researchers in the in SMEs business research (Macpherson and Wilson, 2003).

\subsection{Instrument Development}

All items included our questionnaire were based on the previous research and measured on a sixpoint Likert type scale $(1=$ strongly disagree to $6=$ strongly agree $)$. According to Allen and Rao (2000) it is one of very common in social science research maintained the scale interval-level properties. To test the face validity of all the items included in the questionnaire, first the questionnaire pretested by faculty members. The main intention of the pretest was to assure that the questionnaire is free from vagueness and misunderstanding. After minor correction of the questionnaire we sent it to the respondents attached with a cover letter mentioning the academic purpose of the research.

\section{Data Analysis}

Based on TRA model, to measure the factors that influence ICT adoption, this study find-out the relationship among three components; subjective norms, attitude and intention towards ICT 


\section{Ml Macrothink}

adoption. Based on the regression coefficient and standard error on regression model, the research calculated the mediation relationship. As mentioned earlier, research conducted two different simple regression, the results are in table 1 . The regression analysis provides three tables; model summary table, ANOVA table and Coefficient table (See Appendix). To summarize the result, this study developed a single Table 1 . The $R^{2}$ value is used in the context of statistical models whose main objective is the prediction of future outcomes on the basis of other related information. It is the quantity of variability in a data set that is accounted for by the statistical model (Steel and Torrie, 1960). It provides a measure of how well future results are likely to be predicted by the model.

Table 1. Regression Analysis

\begin{tabular}{llll}
\hline Name of the Test & & $\begin{array}{l}\text { Dep: Intention } \\
\text { Ind: Attitude }\end{array}$ & $\begin{array}{l}\text { and } \\
\text { Dep: Intention and Ind: } \\
\text { Subjective Norms }\end{array}$ \\
\hline $\mathrm{R}$ & & .850 & .652 \\
$\mathbf{R}^{2}$ & & $\mathbf{. 7 2 2}$ & $\mathbf{. 4 2 5}$ \\
Standard Error of & & .51070 & .73471 \\
Estimate & & & \\
Sum of Squares & Regression & 129.505 & 76.219 \\
& Residual & 49.816 & 103.101 \\
Mean Square & Regression & 129.505 & 76.219 \\
& Residual & .261 & .540 \\
F & & 496.539 & 141.199 \\
Significant (ANOVA) & & $\mathbf{. 0 0 0 *}$ & $\mathbf{. 0 0 0 *}$ \\
Unstandard Coefficient & $\beta$ & .448 & .969 \\
(Constant) & Std. Error & .885 & .321 \\
Unstandard Coefficient & $\beta$ & .195 & .776 \\
(Dependant Variable) & Std. Error & .040 & .065 \\
Standard Coefficient & $\beta$ & .850 & .652 \\
t value & Constant & 2.292 & 3.023 \\
& Dependant & 22.283 & 11.883 \\
Significant & Constant & .023 & .003 \\
(Coefficient) & Dependant & $\mathbf{. 0 0 0 *}$ & $\mathbf{. 0 0 0}$ \\
\hline * Statistically significant relation. Source: & & \\
\hline
\end{tabular}

* Statistically significant relation. Source: Developed by the researcher based on regression analysis

Table 1 shows that the $\mathrm{R}^{2}$ value is .722 for the model attitude and intention, which is generally expressed in a percentage. It means the model explains $72.20 \%$ of the variance with intention to adopt ICT, which is good enough. The $\mathrm{R}^{2}$ value .425 for subjective norms and intention means that there is $42.5 \%$ relation between these two factors, which is also above standard. The ANOVA result shows that the both model is highly significant at .000 , which mean there are significant relation among intention, attitude and subjective norms. The coefficient value also 


\section{Mll Macrothink}

shows that the ICT adoption is highly significant. It means that attitude and subjective norms have direct relation with intention of executive to adopt ICT in SME level.

However, though the result shows that the model has been design properly and independent variables have direct relation with dependent variables, but it does not explain whether a mediator variable significantly carries the influence of an independent variable to a dependent variable; i.e., whether the indirect effect of the independent variable on the dependent variable through the mediator variable is significant or not. Hence, this research employed Sobel test to calculate the mediator relation. In statistics, the Sobel test is a technique of testing the significance of a mediation effect. The test is based on the work of Michael E. Sobel, a sociology professor at Columbia University in New York, NY (Sobel, 1982). The Sobel Z statistics is .7863 or $78.63 \%$ and probability is 0.2158 . It means a significant the mediating relationship among there component is highly significant at .05 level or in other word $95 \%$ confident that attitude, and subjective norms have impact on intention to adopt ICT.

Based on the result discussion it has been observed that the executives' intention to adopt ICT is depend on two factors; subjective norms and attitude towards ICT. The attitude has direct relation with intention, since the coefficient is statistically significant at .000 , it means $\mathrm{P}<.01$. In means it is $99 \%$ conform that the intention has been influenced by the attitude of executives towards ICT adoption. Thus, it can be conclude that the first null hypotheses (Attitude of executives has no influence on intention to adopt ICT) is not accepted. Hence, the research accept that attitude of executives has influence on intention to adopt ICT.

The coefficient value for the second model, the relationship between subjective norms and intention also shows statistically significant relation. The coefficient value .000 means $\mathrm{P}<.01$. It means, it is $99 \%$ conform that the subjective norms have impact on intention of executives to adopt ICT. Hence, the results also reveals that the second null hypothesis (Subjective norm has no influence on ICT adoption) of this study is not accepted. Thus, the researcher concluded, intention to adopt has been influenced by subjective norms.

\section{Conclusion and Policy Implication}

The author urges that theory of reasoned action (TRA) model is completely applicable to improve ICT adoption within the SMEs. Since, the study finding shows that ICT adoption within the SMEs is depend on subjective norms and intention, which is main idea of TRA.

To improve the executives intention and their belief (subjective norms) this study recommend, the government and NGOs should work together to arrange training for executives to improve 


\section{$\Lambda$ Macrothink}

their understanding about ICT. It is essential for executives to understand the importance of ICT, which will play significant role towards ICT adoption.

\section{Reference}

Abdullah, M. A. (2002). 7 An Overview of the Macroeconomic Contribution of SMEs in Malaysia. The role of SMEs in national economies in East Asia, 2, 181.

Alam, S. S., \& Ahsan, N. (2007). ICT adoption in Malaysian SMEs from services sectors: Preliminary findings. Journal of Internet Banking and Commerce, 12(3).

Aris, N. M. (2007). SMEs: Building Blocks for Economic Growth1.

Ashrafi, R., \& Murtaza, M. (2008). Use and Impact of ICT on SMEs in Oman. Electronic Journal Information Systems Evaluation, 11(3), 125-138.

Barba-Sánchez, V., Martínez-Ruiz, M. P., \& Jiménez-Zarco, A. I. (2007). Drivers, benefits and challenges of ICT adoption by small and medium sized enterprises (SMEs): A literature review. Problems and Perspectives in Management, 5(1), 104-115.

Bentler, P. M., \& Speckart, G. (1979). Models of attitude-behavior relations. Psychological Review; Psychological Review, 86(5), 452. http://dx.doi.org/10.1037/0033-295X.86.5.452

Chong, A. Y. L., Ooi, K. B., Lin, B., \& Tang, S. Y. (2009). Influence of interorganizational relationships on SMEs'e-business adoption. Internet Research, 19(3), 313-331. http://dx.doi.org/10.1108/10662240910965379

Christiaanse, E., \& Kumar, K. (2000). ICT-enabled coordination of dynamic supply webs. International Journal of Physical Distribution \& Logistics Management, 30(3/4), 268-285. http://dx.doi.org/10.1108/09600030010326019

Cox, M., Cox, K., \& Preston, C. (2000). What motivates teachers to use ICT?

Davidavičiene, V. (2008). Change management decisions in the information age. Journal of Business Economics and Management, 9(4), 299-307. http://dx.doi.org/10.3846/16111699.2008.9.299-307

Fishbein, M., \& Ajzen, I. (1975). Belief, attitude, intention and behaviour: An introduction to theory and research: Addison-Wesley.

Gelauff, G., Klomp, L., Raes, S., \& Roelandt, T. (2004). ICT and Productivity. Fostering productivity: patterns, determinants, and policy implications, 263, 93. 


\section{Macrothink}

Hale, J. L., Householder, B. J., \& Greene, K. L. (2002). The theory of reasoned action. The persuasion handbook: Developments in theory and practice, 259-286. http://dx.doi.org/10.4135/9781412976046.n14

Harvie, C. (2004). East Asian SME Capacity Building, Competitiveness and Market Opportunities in a Global Economy. Faculty of Commerce-Economics Working Papers, 100.

Locke, S. (2004). ICT adoption and SME growth in New Zealand. Journal of American Academy of Business, 4(1/2), 93-102.

Lucchetti, R., \& Sterlacchini, A. (2004). The adoption of ICT among SMEs: evidence from an Italian survey. Small Business Economics, 23(2), 151-168. http://dx.doi.org/10.1023/B:SBEJ.0000027667.55821.53

Miller, K. (2002). Communication theories: McGraw-Hill.

Oulton, N. (2002). ICT and productivity growth in the United Kingdom. Oxford Review of Economic Policy, 18(3), 363-379. http://dx.doi.org/10.1093/oxrep/18.3.363

Perrini, F., Russo, A., \& Tencati, A. (2007). CSR strategies of SMEs and large firms. Evidence from Italy. Journal of business ethics, 74(3), 285-300. http://dx.doi.org/10.1007/s10551-0069235-x

Punchihewa, D. J., \& Wimalaratne, P. (2009). Towards an ICT Enabled Farming Community.

Quayle, M. (2003). A study of supply chain management practice in UK industrial SMEs. Supply Chain Management: An International Journal, 8(1), 79-86. http://dx.doi.org/10.1108/13598540310463387

Saleh, A. S., \& Ndubisi, N. O. (2006). An evaluation of SME development in Malaysia. International Review of Business Research Papers, 2(1), 1-14.

Song, Z., Liu, W., \& Mai, T. (2009). The Sustainable Development of ICTs in China: An Empirical Study of Small and Medium-Sized Enterprises. Chinese Journal of Population, Resources and Environment 7(3).

Wang, Y. (2009). Financing difficulties and structural characteristics of SMEs in China. 